\title{
Quando professores do Ensino Fundamental elaboram situações-problema envolvendo as estruturas multiplicativas: que situações priorizar?
}

\author{
When elementary school teachers develop problem situations involving \\ multiplicative structures: which situations to prioritize?
}

\author{
Ana Paula Perovano
}

\begin{abstract}
Resumo: Neste texto, apresentamos um recorte dos dados do projeto de pesquisa intitulado "As estruturas multiplicativas e a formação de professores que ensinam Matemática na Bahia" (PEM). Nele, analisamos as situações-problema elaboradas por professores do Ensino Fundamental, que atuavam como supervisores do Programa Institucional de Bolsa de Iniciação à Docência (PIBID). Para tratar das estruturas multiplicativas, pautamos nossas reflexões na Teoria dos Campos Conceituais. Desenvolvemos uma pesquisa com abordagem qualitativa de cunho descritivo. Os dados foram coletados por meio de questionários e como resultados identificamos que o foco de trabalho desses professores recai nas situações de proporção simples, da classe um para muitos, e com a grandeza do tipo discreta, o que, a nosso ver, delimita a experiência dos alunos com os conceitos de multiplicação e divisão. Esperamos contribuir no sentido de trazer reflexões em relação ao ensino de tais conceitos.
\end{abstract}

Palavras-chave: Estrutura Multiplicativa. Anos Iniciais. Educação Matemática.

\section{Abstract: In this text, we will present a piece of data from the research project entitled "The multiplicative structures and the formation of teachers who teach mathematics in Bahia" (PEM). In it, we will analyze the problem situations elaborated by elementary school teachers, who acted as supervisors of the Institutional} Teaching Initiation Scholarship Program (PIBID). To treat the multiplicative structures, we base our reflections on the Theory of Conceptual Fields. We developed a research with qualitative approach of descriptive nature. The data were collected through questionnaires and as results we identified that the focus of these teachers work in situations of simple proportion, from class one to many, and with the magnitude of the discrete type, which, in our view, delimits the experience. of students with the concepts of multiplication and division. We hope to contribute to bring reflections on the teaching of such concepts.

Keywords: Multiplicative structure. Early years. Mathematics Education.

\section{Introdução1}

Investigar a prática dos professores no ensino das estruturas multiplicativas é o objetivo geral da pesquisa intitulada "As estruturas multiplicativas e a formação de professores que

\footnotetext{
1 Parte deste texto foi publicado nos anais Encontro Nacional de Educação Matemática, que aconteceu em São Paulo, em julho de 2016.
} 
ensinam Matemática na Bahia" (PEM)² que foi desenvolvida em rede, envolvendo seis Núcleos de Pesquisa da Sociedade Brasileira de Educação Matemática, Regional Bahia (SBEM-BA). Os Núcleos estão situados em Ilhéus, Vitória da Conquista, Feira de Santana, Amargosa, Salvador e Senhor do Bonfim. Neste artigo, traremos um recorte dos dados do núcleo de Vitória da Conquista.

Ao investigar a prática dos professores, diagnosticaremos, também, suas concepções sobre as estruturas multiplicativas e o seu ensino. Diversos autores empregam o termo concepções como sinônimo de crença, opinião e visão (CURY, 1999). Aqui assumimos o termo concepção, tal como foi proposto por Moron e Brito (2005), como sendo a maneira própria de cada indivíduo elaborar, interpretar, representar suas ideias e agir de acordo com elas.

Frequentemente, a competência em operar algoritmos é confundida com o entendimento do conceito de multiplicação e divisão; nesse sentido, o critério utilizado pelo professor para avaliar a compreensão que os alunos possuem sobre esses conceitos é o de fazer contas com precisão (CORREA e SPINILLO, 2004).

As autoras destacam que tratar o ensino de conceitos matemáticos sob essa perspectiva apresenta obstáculos: inicialmente, restringe a Matemática ao cálculo ou ao desenvolvimento de algoritmos, ignora a diferença entre operação e o algoritmo, sendo que este último "se refere a um conjunto de procedimentos que leva à execução de uma dada operação; enquanto a operação implica transformações realizadas sobre números, quantidades, grandezas e medidas" (CORREA e SPINILLO, 2004, p. 105). Tratar o ensino de multiplicação e divisão restrito a operar algoritmos incorre, ainda,

no equívoco de desconhecer que o processo de aquisição dos conceitos matemáticos, tomando como ponto de vista psicológico, vai se referir não apenas ao domínio de um invariante lógico-matemático, mas também aos sistemas simbólicos que servem de suporte a expressão e à variedade de situações que the conferem significado. (CORREA e SPINILLO, 2004, p. 105).

Diante do exposto, percebemos que o conceito de multiplicação e divisão está além do desenvolvimento de algoritmos. Sobre isso, os Parâmetros Curriculares Nacionais de Matemática - PCN (BRASIL, 1997) orientam que o trabalho a ser realizado com as operações (adição, subtração, multiplicação e divisão) precisa centrar-se na compreensão dos diferentes significados que cada uma delas assume e nas relações existentes entre elas.

\footnotetext{
2 Pesquisa financiada pela Fundação de Amparo à Pesquisa do Estado da Bahia (FAPESB), com termo de outorga
} n PES0019/2013. 
Apesar da orientação dos PCN, o que ainda se observa é que a multiplicação continua sendo apresentada apenas como uma adição de parcelas repetidas. Porém, "o que se constata é que essa abordagem não é suficiente para que os alunos compreendam e resolvam outras situações relacionadas à multiplicação, mas apenas aquelas que são essencialmente situações aditivas" (PIRES, 2012, p. 132). Ou seja, tratar a multiplicação apenas como adição de parcelas repetidas não é suficiente para a aquisição do conhecimento multiplicativo (MAGINA, SANTOS e MERLINI, 2014), pois, ao repetir a mesma classe de problemas, que solicitam o mesmo modo de pensamento por parte dos alunos, "o professor pode levar o aluno a desenvolver concepções ou mesmo estratégias, que dificultam a aquisição do próprio conceito em foco, assim como de outros, limitando sua competência à resolução de problemas daquele tipo. (GITIRANA et al., 2014, p. 42).

Nesse sentido, entendemos que se faz necessário, ao trabalhar com a multiplicação e a divisão, oferecer à criança uma diversidade de situações entrelaçadas aos conceitos para que esse e seus diferentes significados sejam desenvolvidos por ela.

Indicaremos brevemente, a seguir, as estruturas multiplicativas que apresentam uma classificação para problemas que dão significados às operações de multiplicação e divisão. Endentemos ser importante o conhecimento desta classificação pelos professores para que não limitem as situações-problema apresentadas às crianças.

\section{Campo conceitual multiplicativo ou estruturas multiplicativas}

Desenvolvida por Gerárd Vergnaud, a Teoria dos Campos Conceituais assume como premissa que o conhecimento está organizado em campos conceituais, cujo domínio, por parte do sujeito, ocorre ao longo de um largo período, vindo da experiência, maturidade e aprendizagem (VERGNAUD, 1982, p. 40). Para o autor, campo conceitual é um conjunto informal e heterogêneo de problemas, situações, conceitos, relações, estruturas, conteúdos e operações de pensamento, conectados uns aos outros e, provavelmente, entrelaçados durante o processo de aquisição.

Assim, para aprender um conceito é necessário ter contato com diferentes situações que envolvam esse conceito. Cabe destacar, também, que cada situação traz consigo mais de um conceito e, a aquisição de um conhecimento, por mais simples que seja, não pode ser adquirido a partir da vivência de uma única situação (GITIRANA et al., 2014). 
De acordo com Magina, Santos e Merlini (2014), as estruturas multiplicativas, ou campo conceitual multiplicativo, são diversas situações reunidas em que, para a sua abordagem, discussão e resolução, são necessários diferentes tipos de conceitos, procedimentos e representações, além de exigirem uma operação de multiplicação, divisão ou as duas juntas.

Gitirana et al. (2014) alertam que considerar a multiplicação como adição de parcelas repetidas pode causar obstáculo no entendimento da propriedade comutativa da multiplicação a qual garante que, em uma multiplicação, a ordem dos fatores não altera o produto. Para elucidar esse obstáculo, as autoras apresentam o seguinte exemplo:

\footnotetext{
Em cada pacote de figurinhas vêm 3 figurinhas. Quantas figurinhas se obtêm com 4 pacotes?

Pensando como adição de parcelas repetidas:

3 figurinhas +3 figurinhas +3 figurinhas +3 figurinhas $=(4 \times 3$ figurinhas $)$

4 pacotes +4 pacotes +4 pacotes $=(3 \times 4$ pacotes $)$
}

(GITIRANA et al. 2014, p. 25)

No primeiro caso, encontraríamos 12 figurinhas e, no segundo teríamos 12 pacotes, o que não corresponde ao sentido do problema. Dessa forma, "um raciocínio direto da comutatividade por adição repetida, leva à troca do significado do problema, o que não tem sentido na Matemática e, muito menos, para o aluno" (GITIRANA et al., 2014, p. 25).

Com base no que as autoras apresentam, é possível perceber que, quando o professor resolve situações multiplicativas como adição de parcelas repetidas, é possível haver a troca de significados do problema, o que pode limitar o raciocínio multiplicativo por parte do aluno, fazendo com que a verdadeira estrutura conceitual da multiplicação tenda a ser mascarada/disfarçada.

Santos (2012) afirma não ser contrário à introdução da multiplicação por meio de adição de parcelas iguais, pois esse procedimento aponta a continuidade entre a adição e essa operação. 0 autor admite, porém, que essa filiação, entre o campo conceitual aditivo e o multiplicativo, é limitada e local, pois outros tipos de situações podem requerer variados tipos de esquemas de ação, o que sugere, de certa maneira, uma ruptura entre eles.

Consideramos ser de grande importância que o professor que ensina Matemática conheça o campo conceitual multiplicativo, pois, com base nele, será capaz de elaborar problemas de forma a abranger o maior número possível de situações que envolvam os diferentes significados da multiplicação e divisão. 
Para melhor entendimento dessas situações, na Figura 1, a seguir, classificamos cada problema multiplicativo de acordo com algumas de suas especificidades.

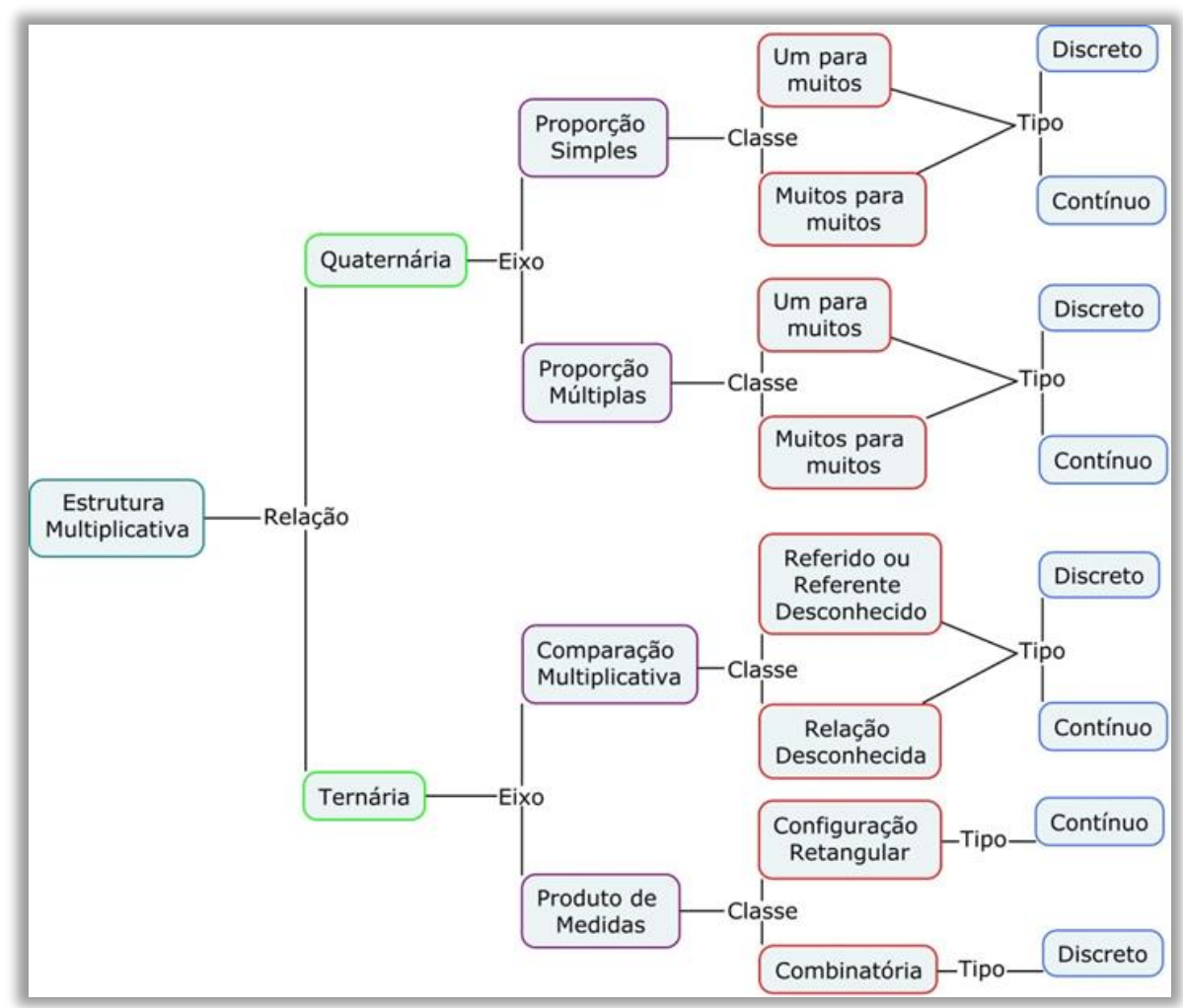

Figura 1: Esquema do campo conceitual multiplicativo (Adaptado de Merlini, Magina e Santos, 2010)

As estruturas multiplicativas possuem duas relações que são classificadas como quaternária e ternária (MERLINI, MAGINA e SANTOS, 2010). Fazem parte das relações quaternárias as situações em que há duas relações entre duas ou mais grandezas distintas; já as relações ternárias são aquelas situações em que há o produto de grandezas de diferentes ou de mesma natureza, que se combinam para gerar uma terceira grandeza.

Estão inclusos nas relações quaternárias os eixos proporções simples e proporções múltiplas. A proporção simples é referida por Magina, Santos e Merlini (2014) como situações em que se têm duas relações entre apenas duas grandezas. Exemplo: Se Ricardo ganha dos seus pais 10 livros a cada ano, quantos livros Ricardo terá ganhado daqui a 5 anos?

A proporção simples, por sua vez, é dividida em duas classes, um para muitos e muitos para muitos. Merlini, Magina e Santos (2010) as definem como: na classe um para muitos, tem-se em uma das relações uma unidade de uma grandeza relacionada à uma quantidade qualquer de outra grandeza. Exemplo: Em uma caixa tem 3 bolinhos. Quantos bolinhos têm em 5 caixas? $\mathrm{Na}$ classe muitos para muitos tem-se, nas duas relações, duas ou mais unidades de uma grandeza 
relacionada à duas ou mais unidades da outra grandeza. Exemplo: Maria Fernanda compra sete pães por $R \$ 3,00$. Quantos pães ela comprará com $R \$ 5,00$ ?

A proporção múltipla se refere à duas relações entre três ou mais grandezas distintas (MAGINA, SANTOS e MERLINI, 2014). Esse eixo também é dividido em duas classes, tal como na proporção simples, um para muitos e muitos para muitos.

Nas relações ternárias tem-se os eixos comparação multiplicativa e produto de medidas. Na comparação multiplicativa, há uma relação de multiplicação entre dois elementos, como por exemplo, a relação de dobro, triplo e metade (MAGINA, SANTOS e MERLINI, 2014). Esse eixo possui duas classes, a relação desconhecida, e referido ou referente desconhecido.

As classes referido desconhecido ou referente desconhecido são identificadas quando o elemento que está sendo mencionado ou tomado como referência é desconhecido no problema. Exemplos: Mariana tem 15 anos e sua irmã Júlia é duas vezes mais velha que ela. Qual a idade de Júlia? (referido desconhecido). Júlia tem 30 anos e é duas vezes mais velha que sua irmã Mariana. Quantos anos Mariana têm? (referente desconhecido). Já na relação desconhecida, a proporção multiplicativa entre os elementos não está explícita no problema. Exemplo: Marcela comprou um celular por $R \$ 300,00$, enquanto Pedro pagou $R \$ 600,00$ pelo mesmo celular. Quantas vezes mais que Marcela, Pedro pagou pelo celular?

O produto de medidas é o segundo eixo das relações ternárias e é dividido em duas classes, a configuração retangular e a combinatória.

De acordo com Merlini, Magina e Santos (2010), configuração retangular é aquela que situações envolvendo o cálculo de área de retângulos. Exemplo: Seu Jorge tem 36 metros de arame para cercar um terreno retangular do qual um dos lados mede 10 metros. Qual a área do terreno a ser cercado por Seu Jorge?

A classe combinatória é aquela em que a resolução do problema é feita por meio de agrupamentos entre dois ou mais elementos de domínios distintos (MAGINA, SANTOS e MERLINI, 2014). Exemplo: Numa sorveteria há 9 tipos de sorvetes e 8 tipos de coberturas diferentes. Quantas combinações diferentes de sorvete com cobertura os clientes da sorveteria podem fazer?

Conforme já sinalizamos, consideramos importante que o professor que ensina Matemática conheça as estruturas multiplicativas e sua classificação, aqui brevemente 
apresentada, pois, apresentar aos alunos situações-problema que envolvam essa diversidade de raciocínio possibilita mais oportunidades de ampliação do conhecimento dos alunos sobre multiplicação e divisão.

\section{Metodologia}

Nossa intenção é obter a perspectiva dos participantes, "suas práticas do dia a dia e em seu conhecimento cotidiano relativo à questão em estudo" (FLICK, 2009, p. 16) e, dessa forma, empregamos uma abordagem qualitativa. Essa pesquisa possui um cunho descritivo, pois se "deseja descrever ou caracterizar detalhes de uma situação, um fenômeno ou um problema". (FIORENTINI e LORENZATO, 2006, p. 70)

Participaram de nossa investigação, 12 professores que lecionam Matemática em escolas públicas, localizadas na cidade de Vitória da Conquista, na região Sudoeste da Bahia. Neste artigo, nosso recorte será para os três professores que lecionam nos anos finais do Ensino Fundamental. Do grupo de professores participantes, esses participam como supervisores do PIBID. Entendemos que esses professores acompanham, participam, orientam e viabilizam o trabalho dos bolsistas de iniciação à docência, na escola, em conjunto com o coordenador do subprojeto a que o PIBID esteja vinculado.

O instrumento de coleta de dados foi o questionário, que é uma forma tradicional de coleta de informações (FIORENTINI e LORENZATO, 2006). Aplicamos dois questionários, um referente ao perfil profissional dos professores e outro referente à elaboração de situações-problema envolvendo multiplicação e divisão.

Os dados obtidos com a aplicação dos questionários foram agrupados em categorias. Para Fiorentini e Lorenzato (2006), tal método se trata de um processo de seleção ou de organização de informações em categorias estabelecidas, ou seja, em classes ou conjuntos que contenham elementos ou características comuns. Essas categorias foram delineadas nos momentos de discussões e reflexões e fundamentadas em nosso referencial teórico. 


\section{Resultado e discussões}

Nesta seção apresentaremos um recorte dos resultados encontrados com a aplicação do questionário referente ao perfil e à elaboração de situações-problema envolvendo multiplicação e divisão.

Sobre a formação dos professores, os três possuem curso superior, um sendo formado em Ciências Exatas, e dois com Licenciatura em Matemática. Todos são pós-graduados e possuem 15 anos de experiência lecionando Matemática.

Em nosso ponto de vista, consideramos tratar-se de profissionais experientes, pois já atravessaram a fase de estabilização e de consolidação (do terceiro ao sétimo ano) em que o professor está mais centrado em si mesmo, na disciplina e nos alunos (TARDIF e RAYMOND, 2000). Na visão desses autores, com o passar do tempo, o professor torna-se "aos seus próprios olhos e aos olhos dos outros - um professor, com sua cultura, seu éthos, suas ideias, suas funções, seus interesses etc." (TARDIF e RAYMOND, 2000, p. 210).

Em relação aos recursos didáticos utilizados pelos professores é unanime a utilização do livro didático. O material pedagógico da Secretaria de Educação é utilizado por um professor, enquanto outro optou por utilizar o ábaco.

Cada situação elaborada pelos professores foi classificada, inicialmente, considerando tarefa e questão conforme categorias apresentadas na Figura 2.

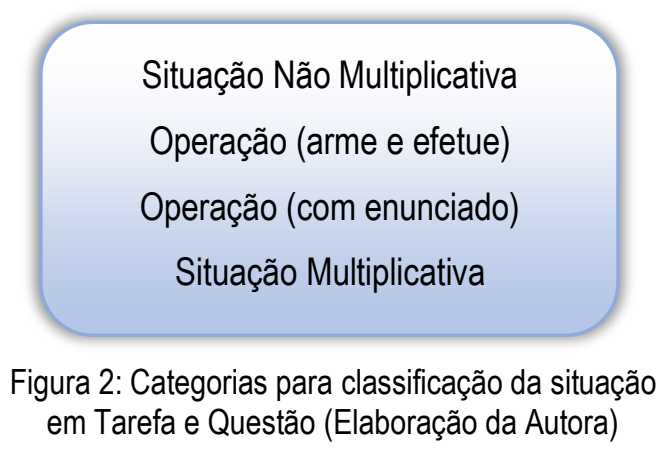

Cabe mencionar que, para a validação da classificação de cada situação elaborada pelos professores, contamos com a colaboração de cinco juízes independentes que classificaram os problemas separadamente. Caso houvesse divergência entre as classificações, um sexto juiz se juntaria aos cinco, e os seis debateriam sobre o problema, chegando a um consenso.

Situação(ões) Não Multiplicativa(s): são aquelas em que a sua resolução não exige nenhuma operação de multiplicação ou divisão. 
Operação (arme e efetue): nessa categoria estão as situações em que se solicita ao aluno a resolução da operação multiplicação e divisão, também sem lidar com relações entre grandezas. Normalmente, apresenta a utilização de algoritmos.

Operação (com enunciado): são classificadas nessa categoria as situações em que se solicita, no enunciado, efetuar operação de multiplicação ou divisão, mas sem fazer o uso das relações entre grandezas.

Situação(ões) Multiplicativa(s): são situação(ões) nas quais se exige a utilização da operação de multiplicação e/ou divisão em sua resolução, lidando com relações entre grandezas.

O Gráfico 1, a seguir, apresenta o primeiro nível de categorização das situações-problema elaboradas pelos professores.

Gráfico 1: Classificação das questões produzidas pelas professoras

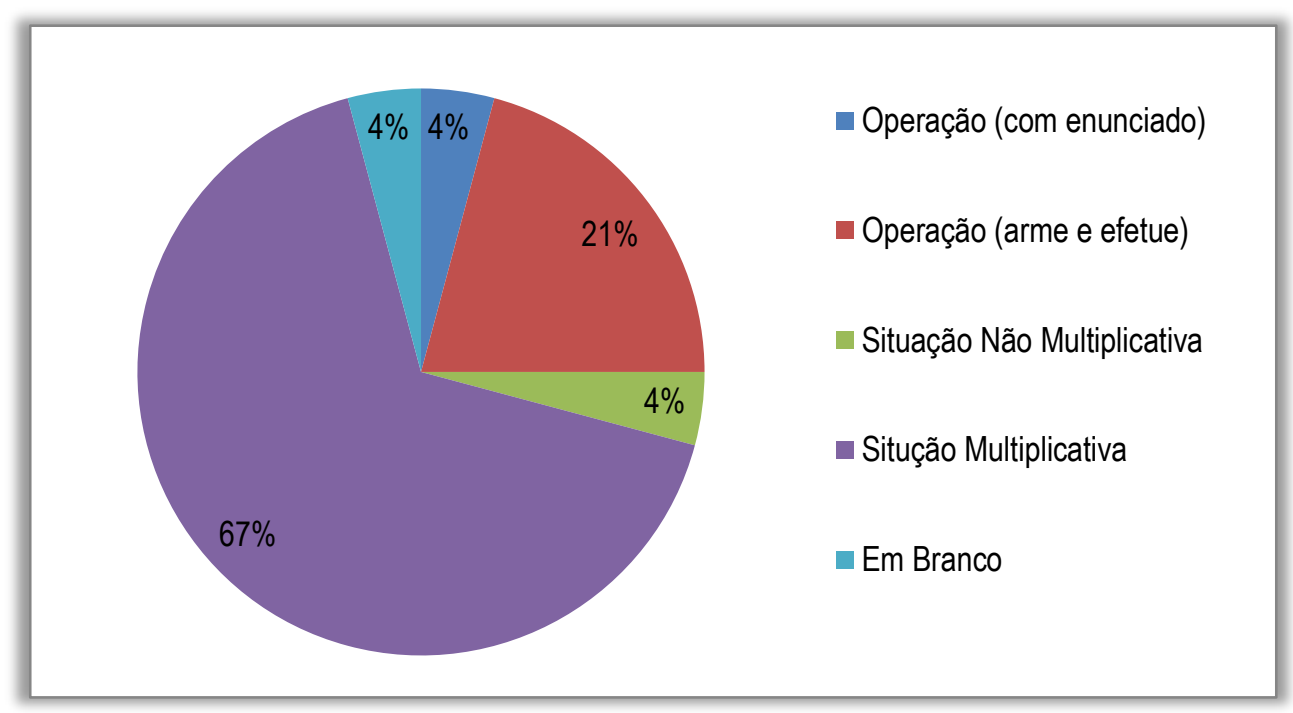

Fonte: Elaboração da Autora

A partir dos dados retratados no Gráfico 1, percebemos que a maioria das questões elaboradas pelos professores foram classificadas como situações multiplicativas (16 situações); cinco situações foram classificadas como operação (arme e efetue); uma situação foi classificada como operação (com enunciado); uma situação não multiplicativa e uma foi deixada em branco. Apresentaremos o extrato de algumas das questões elaboradas.

A Figura 3 retrata uma das questões classificadas como operação (arme e efetue). 
Prob. 2:

Quil o mímeno que maltiplicador por

8 Tirér o resultado 72 ?

Figura 3: Questão classificada como Operação (Arme e Efetue) (Dados da Pesquisa)

Observamos que, na situação elaborada, 0 aluno deve encontrar a resposta para $\mathrm{x} \cdot 8=$ 72, não lidando com as relações entre as grandezas. A Figura 4 é representativa da classificação como situação não multiplicativa.

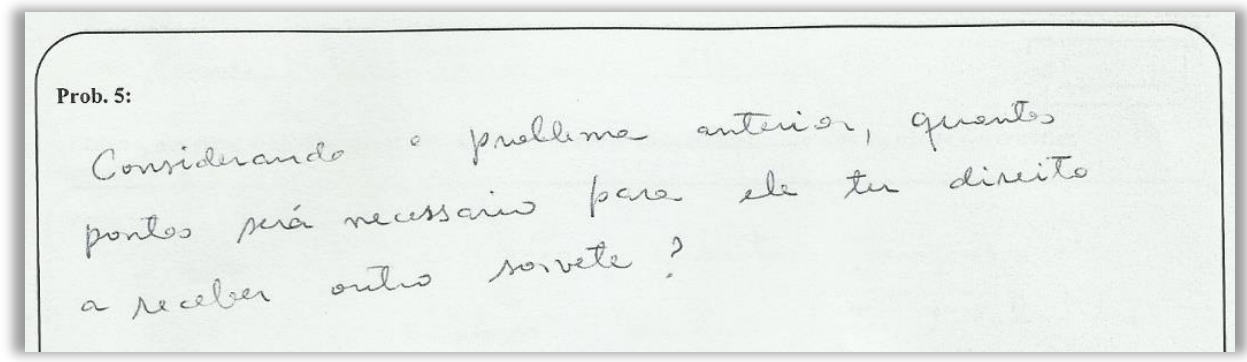

Figura 4: Questão classificada como Não Multiplicativa (Dados da Pesquisa)

Como podemos perceber pela Figura 4, tal situação recorre à questão anteriormente elaborada pelo professor: "Um amigo conseguiu acumular 270 pontos na promoção de uma sorveteria. Se cada 50 pontos correspondem a um sorvete, quantos sorvetes ele vai receber?" Notemos que, para solucionar a questão apresentada na Figura 4, não é necessária a utilização da operação de multiplicação ou divisão. 0 aluno, ao resolver a questão anterior, vai encontrar que o amigo conseguiu cinco sorvetes e restaram 20 pontos. Na questão proposta, e exposta na Figura 4, é solicitada ao estudante a diferença entre a quantidade de pontos necessários para ganhar o sorvete da quantidade de pontos que o amigo tem, portanto solicita que o estudante efetue uma subtração.

Todas as situações multiplicativas ( 16 situações) foram classificadas como adequadas, ou seja, não possuíam imprecisões quanto a fatos numéricos a serem operados, nem ausência de informação, nem existência de confusão acerca do que é solicitado no enunciado. Essas situações foram classificadas de acordo com a Figura 1, para as quais encontramos 12 situações classificadas como relação quaternária, e quatro situações como relação ternária. 
Todas as questões das relações quaternárias foram categorizadas como pertencentes ao eixo proporção simples da classe um para muitos. Dessas, três foram classificadas como utilizando grandezas do tipo contínuas e nove utilizando grandezas do tipo discreta. A Figura 5 ilustra uma das situações-problema elaborada.

Prob.1: Cinema da Gidocle Nova Esperomar tem 4 ilas cons \& tadeiras. Guontors cordiinas tem nesse limena?

Figura 5: Questão classificada nas relações quaternárias, do eixo proporção simples e classe um para muitos (Dados da Pesquisa)

Na situação ilustrada na Figura 5, observamos haver a quantidade de filas de um cinema (grandeza), a quantidade de cadeiras por fila (grandeza) e se solicita a quantidade de cadeiras que o cinema possui (grandeza). Essa situação, por se tratar da classe um para muitos, é resolvida pelos alunos, utilizando a multiplicação da quantidade de cadeiras pela quantidade de filas, sem atentarem para a relação de proporcionalidade:

\begin{tabular}{c|c}
$\begin{array}{c}\text { Quantidade de } \\
\text { Filas }\end{array}$ & $\begin{array}{c}\text { Quantidade de } \\
\text { Cadeiras }\end{array}$ \\
\hline $1 \longrightarrow 8$ \\
\hline $4 \longrightarrow x$
\end{tabular}

Consideramos que, ao trabalhar as situações de proporção simples da classe um para muitos, explicitar a relação de proporcionalidade facilita a utilização das estratégias:
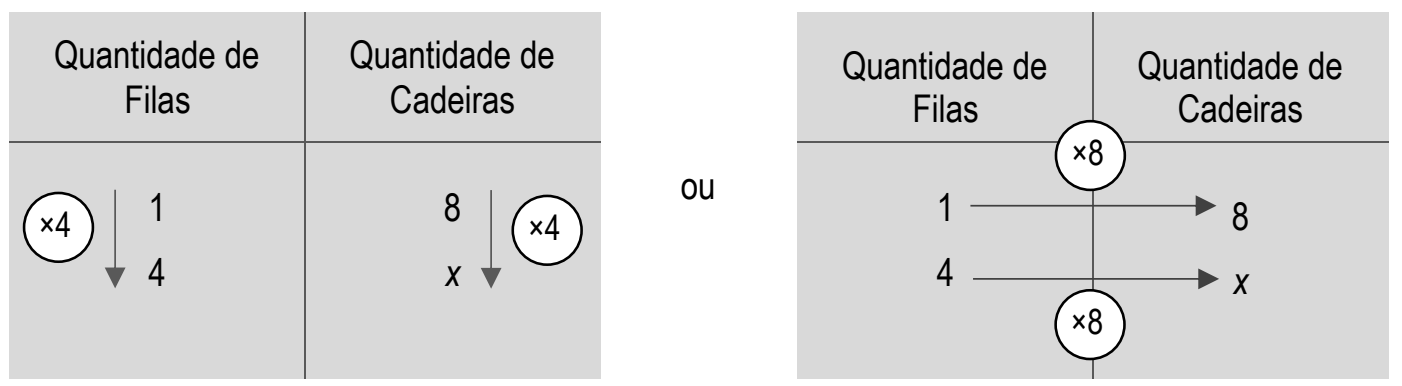

No primeiro caso, o aluno identifica a razão (operador escalar) pela qual se deve multiplicar a quantidade de filas e a quantidade de cadeiras e, no segundo caso, identifica a taxa de proporcionalidade (operador funcional) que relaciona as duas grandezas de naturezas diferentes. 
As quatro questões da relação ternária utilizavam grandeza do tipo discreta, dentre as quais, duas envolviam o eixo produto de medida da classe combinatória, e duas foram classificadas no eixo comparação multiplicativa da classe referido desconhecido. As Figuras 6 e 7, a seguir, ilustram situações classificadas como pertencentes à relação ternária.

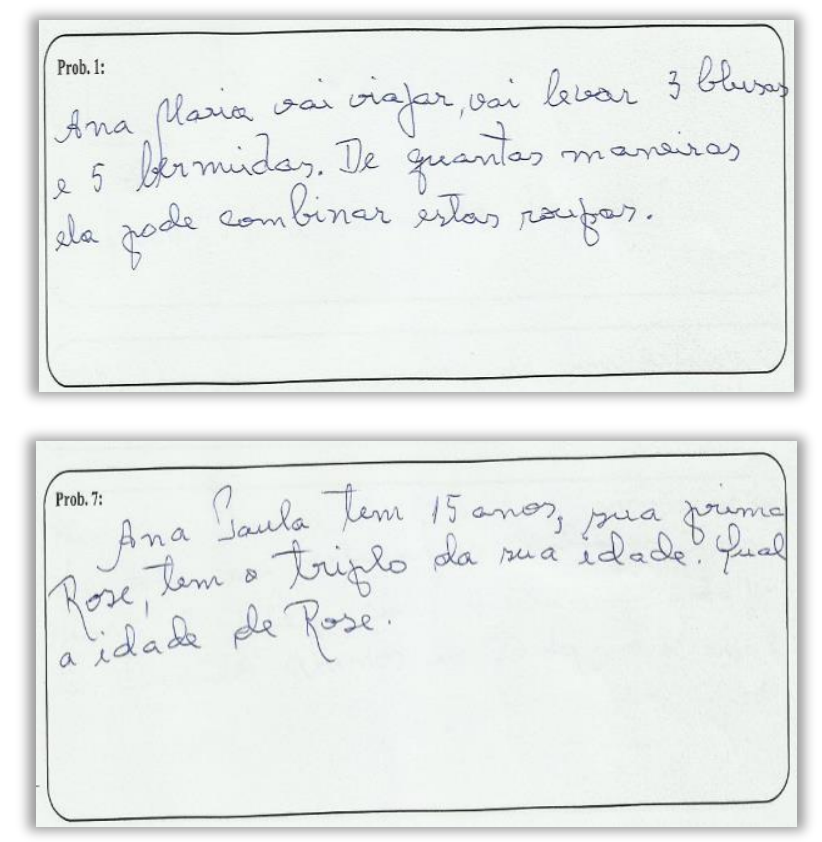

Figuras 6 e 7: Situações classificadas nas relações ternárias: eixo produto de medida, classe combinatória e eixo comparação multiplicativa, classe referido desconhecido, respectivamente (Dados da Pesquisa)

A situação exibida na Figura 6 solicita que o aluno responda a quantidade de possibilidades que Ana Maria vai poder combinar para se vestir, utilizando 3 blusas e 5 bermudas. Trata-se de uma situação de combinatória, em que a quantidade de blusas é uma grandeza e a quantidade de bermuda é outra grandeza e que, ao realizar a junção das duas, obtém-se outra grandeza que é a quantidade de possibilidades que Ana Maria terá para se vestir.

Na situação apresentada na Figura 7, tem-se o referente (idade de Ana Paula) a relação (o triplo da idade) e o referido (Rose, prima de Ana Paula) é desconhecido e é o que o aluno deve encontrar. Gitirana et al. (2014) afirmam que, no campo das estruturas multiplicativas, as situações que envolvem comparação multiplicativa são dominadas rapidamente pelos estudantes.

Do total das situações elaboradas, consideramos positivo que mais da metade delas eram situações multiplicativas adequadas. Entretanto, ponderamos que o foco de trabalho desses professores investigados, possivelmente, recai nas situações de proporção simples, da classe um 
para muitos e com a grandeza do tipo discreta, o que, a nosso ver, delimita a experiência dos alunos com os conceitos de multiplicação e divisão.

\section{Considerações}

Ao analisar as situações-problema elaboradas por três professores dos anos finais do Ensino Fundamental que atuam como supervisores do Programa Institucional de Bolsa de Iniciação à Docência (PIBID), percebemos que os professores investigados privilegiam as relações quaternárias da relação proporção simples da classe um para muitos e com a grandeza do tipo discreta - 12 situações dentre as 16 situações classificadas como multiplicativa.

Consideramos que manter o tipo de situações-problema limita a experiência do aluno, não permitindo que se aproprie do conceito, pois, segundo a Teoria dos Campos Conceituais, a compreensão de um conceito, por mais simples que seja, não emerge apenas de um tipo de situação. Assim, destacamos ser "preciso que o professor esteja atento à complexidade de cada tipo de situação, para não ficar repetindo problemas que requeiram o mesmo raciocínio, ao longo da formação inicial do aluno" (GITIRANA et al., 2014, p. 41). Ao atentar para a complexidade de cada tipo de situação e apresentá-las aos alunos, o professor possibilitará mais oportunidades de ampliação do conhecimento de seus estudantes sobre multiplicação e divisão.

Assim, percebemos ser necessária a reflexão do professor a respeito de sua prática docente, no que diz respeito ao campo conceitual multiplicativo, no sentido de não limitar as situações-problema apresentadas a seus alunos.

\section{Referências}

BRASIL. Ministério da Educação. Secretaria de Educação Fundamental. Parâmetros Curriculares Nacionais: Matemática. Brasília: MEC/SEF, 1997.

CORREA, Jane; SPINILLO, Alina Galvão. O desenvolvimento do raciocínio multiplicativo em crianças. In: PAVANELLO, Regina Maria. (Org.). Matemática nas séries iniciais do Ensino Fundamental: a pesquisa e a sala de aula. São Paulo: SBEM, 2004, p. 103-127.

CURY, Helena Noronha. Concepções e crenças dos professores de Matemática: pesquisas realizadas e significado dos termos utilizados. Bolema, Rio Claro, v. 12, n. 13, p. 29-43, 1999.

FIORENTINI, Dario; LORENZATO, Sérgio Apparecido. Investigação em Educação Matemática: percursos teóricos e metodológicos. Campinas: Autores Associados, 2006. 
FLICK, Uwe. Introdução à pesquisa qualitativa. Tradução de Joice Elias Costa. Porto Alegre: Artmed, 2009

GITIRANA, Veronica; MAGINA, Sandra; CAMPOS, Tânia; SPINILLO, Alina. Repensando multiplicação e divisão: contribuição da Teoria dos Campos Conceituais. São Paulo: PROEM, 2013.

MAGINA, Sandra; SANTOS, Aparecido dos; MERLINI, Vera Lucia. O raciocínio de estudantes do Ensino Fundamental na resolução de situações das estruturas multiplicativas. Ciência e Educação, Bauru, v. 20, n. 2, p. 517-533, 2014.

MERLINI, Vera Lucia; MAGINA, Sandra; SANTOS, Aparecido dos. O desempenho dos estudantes de $4^{a}$ série do Ensino Fundamental frente a problemas de estrutura multiplicativa. In: ENCONTRO NACIONAL DE EDUCAÇÃO MATEMÁTICA, 10, 2010, Salvador. Anais do X ENEM: Educação Matemática, Cultura e Diversidade. Salvador: SBEM, 2010, p. 1-11.

MORON, Cláudia Fonseca; BRITO, Márcia Regina Ferreira de. Atitudes e concepções dos professores de educação infantil em relação à matemática. In: BRITO, Márcia Regina Ferreira de. (Org.). Psicologia da Educação Matemática: teoria e pesquisa. Florianópolis: Insular, 2005, p. 263277.

PIRES, Célia Maria Carolino. Educação Matemática: conversa com professores dos anos iniciais. São Paulo: Zé-Zapt Editora, 2012.

SANTOS, Aparecido dos. Processos de formação colaborativa com foco no campo conceitual multiplicativo: um caminho possível com professoras polivalentes. 2012. 340f. Tese (Doutorado em Educação Matemática) - Faculdade de Ciências Exatas e Tecnologias. Pontifícia Universidade Católica de São Paulo. São Paulo.

TARDIF, Maurice; RAYMOND, Danielle. Saberes, tempo e aprendizagem do trabalho no magistério. Educação \& Sociedade, Campinas, v. 21, n. 73, p. 209-244, dez. 2000.

VERGNAUD, Gerárd. A classification of cognitive tasks and operations of thought involved in addition and subtraction problems. In: CARPENTER, Thomas P.; MOSER, James M.; ROMBERG, Thomas A. (Ed.). Addition and subtraction: a cognitive perspective. Hillsdale: Lawrence Erlbaum, 1982, p. 39-59. 